\title{
The population history of the deep-sea demersal fish Bothrocara hollandi in the Japan Sea revealed by tandem repeat units in the mitochondrial non-coding region
}

\author{
YASUmi Kodama \& Shigeaki KoJIMA* \\ Ocean Research Institute, University of Tokyo, 1-15-1 Minamidai, Nakano, Tokyo 164-8639, Japan
}

Received 7 January 2009; Accepted 25 May 2009

\begin{abstract}
We determined the nucleotide sequences of the non-coding region between the genes for tRNA ${ }^{\text {Thr }}$ and tRNA $^{\text {Pro }}$ in 433 specimens of the deep-sea demersal fish Bothrocara hollandi obtained from the Japan Sea and the Okhotsk Sea. This region consisted of 1-3 copies of sequences, which originated from the duplication of the $5^{\prime}$-region of the tRNA ${ }^{\text {Pro }}$ gene. All the individuals from the Okhotsk Sea have two copies and those from the Japan Sea were shown to have 1-3 copies. Of the individuals obtained from the Japan Sea, those with more than one copy and those with a single copy corresponded to Group A and Group B, respectively, which have been defined in a previous study. On the other hand, a closely related species, Bothrocara tanakae, has a single copy, and no non-coding region was detected for the congeneric species Bothrocara molle. Duplication of the unit might have occurred three times during the evolution of $B$. hollandi. During the last glacial maximum (LGM) when most of the Japan Sea was anoxic, ancestors of Group A would have inhabited the shallower areas of the Japan Sea which did not become anoxic while those of Group B might have survived in other refuges in the Japan Sea. Low genetic diversity of Group B suggests that a severe bottleneck might have occurred in the population size of an ancestral population of Group B during the LGM.
\end{abstract}

Key words: Bothrocara hollandi, Japan Sea, mitochondrial DNA, non-coding region, tandem repeat

\section{Introduction}

The Japan Sea eelpout Bothrocara hollandi (Jordan \& Hubbs) is a relatively small eelpout of the family Zoarcidae and one of the most dominant species of deep-sea demersal fishes in the Japan Sea. The population of this species in the Japan Sea was shown to be genetically distinct from those in the Okhotsk Sea, which is attributable to shallow depths of the straits that function as a distributional barrier between them (Kodama et al. 2008): the Soya Strait (55-m deep) and the Mamiya Strait (15-m deep).

On the basis of the nucleotide sequences of a part (approximately 250 base pairs (bp)) of the mitochondrial control region (CR), Kojima et al. (2001) demonstrated that 296 specimens of $B$. hollandi collected at 17 sites in the southwestern Japan Sea (extending off Yamaguchi Prefecture to the southern tip of Hokkaido) could be separated into two genetically distinct groups, namely, a monophyletic group with a relatively high genetic diversity (Group A) and a paraphyletic group with a relatively low genetic diversity (Group B). Specimens of the former group

*Corresponding author: Shigeaki Kojima; E-mail, kojima@ori.u-tokyo.ac.jp were collected only from sampling sites shallower than $1,100 \mathrm{~m}$, which were found predominantly off the western part of Honshu Island (the Japanese mainland). Those of the latter group were collected from all sampling sites. Kojima et al. (2001) suggested that these two groups had been isolated from each other in distinct refuges during the last glacial period and were brought into contact secondarily thereafter.

Previous phylogenetic studies based on the nucleotide sequences of CR (Kojima et al. 2001, Kadama et al. 2008) failed to show the monophyly of individuals of Group A with a high bootstrap probability; therefore, another molecular marker was required to confirm this. Recently, a noncoding region was discovered between the tRNA ${ }^{\text {Thr }}$ and tR$\mathrm{NA}^{\mathrm{Pro}}$ genes of $B$. hollandi (Kodama 2005). Since non-coding regions are expected to show a high rate of molecular evolution, they may serve as better molecular markers than $\mathrm{CR}$ for investigating the intraspecific phylogeny. In the Japan Sea, which is a semi-enclosed marginal sea, the large environmental changes have occurred with the alternation of the glacial and interglacial periods during the Quaternary (Itaki et al. 2004). Investigations of genetic population structure of marine organisms in this sea area will offer use- 
ful information to estimate the effect of the future environmental changes caused by human activities. In the present study, we attempt to confirm the monophyly of Group A and reconstruct the population history of $B$. hollandi, on the basis of this non-coding region.

\section{Materials and Methods}

We used mitochondrial DNA fragments flanking the 3 'region of the $\mathrm{tRNA}^{\mathrm{Thr}}$ gene and either the $5^{\prime}$-region of the $\mathrm{CR}$ or that of $12 \mathrm{~S}$ ribosomal DNA that were amplified by polymerase chain reaction (PCR) and purified in the previous study (Kodama et al. 2008). Using theses DNA fragments, the region between the $\mathrm{tRNA}^{\mathrm{Thr}}$ and $\mathrm{tRNA}^{\text {Pro }}$ genes were sequenced for 452 specimens of Bothrocara hollandi obtained from the Japan Sea and the Okhotsk Sea, three specimens of a closely related species Bothrocara tanakae (Jordan \& Hubbs), and a single specimen of the congeneric species Bothrocara molle Bean by using BigDye Terminator Cycle Sequencing Kit Version 3.0 (Applied Biosystems, Foster City, CA). The following primers were used: CR3-H, 5'-GAAACCCCTTGCACCCGTGG-3' (Kodama et al. 2008); CR-2, 5'-CRAATACTTGTCCCTCACCCTC-3' (Kojima et al. 2001); and/or ZCR4-H, 5'CCTTGAATTCGTATAGATGTTACC-3', which was synthesized on the basis of the determined sequences. The sequences were obtained using an ABI 3100 automated DNA sequencer (Applied Biosystems).

Specimens of $B$. hollandi from the Japan Sea were classified into Group A and Group B according to the classification of Kojima et al. (2001) on the basis of the nucleotide sequences of CR reported in Kodama et al. (2008). In the median-joining network (Kodama et al. 2008), the two groups were discriminated by a single insertion/deletion (indel) and a single nucleotide substitution. The first group containing 32 haplotypes from 357 specimens corresponded to Group B and the second group containing 19 haplotypes obtained from 65 specimens corresponded to Group A. Specimens of Group A were obtained at the depths shallower than $1,100 \mathrm{~m}$ in the southwestern part as well as the northern part of the Japan Sea.

\section{Results}

Non-coding regions were detected between the tRNA ${ }^{\text {Thr }}$ and tRNA ${ }^{\text {Pro }}$ genes in all specimens of Bothrocara hollandi and Bothrocara tanakae (Fig. 1), while no non-coding region were recognized in a Bothrocara molle specimen. The nucleotide sequences of this region were determined for 433 of 452 specimens of $B$. hollandi and for all specimens of $B$. tanakae. For the remaining specimens of $B$. hollandi, sequences could not be determined probably due to heteroplasmy. Nucleotide sequences of this region were identical among three specimens of $B$. tanakae.

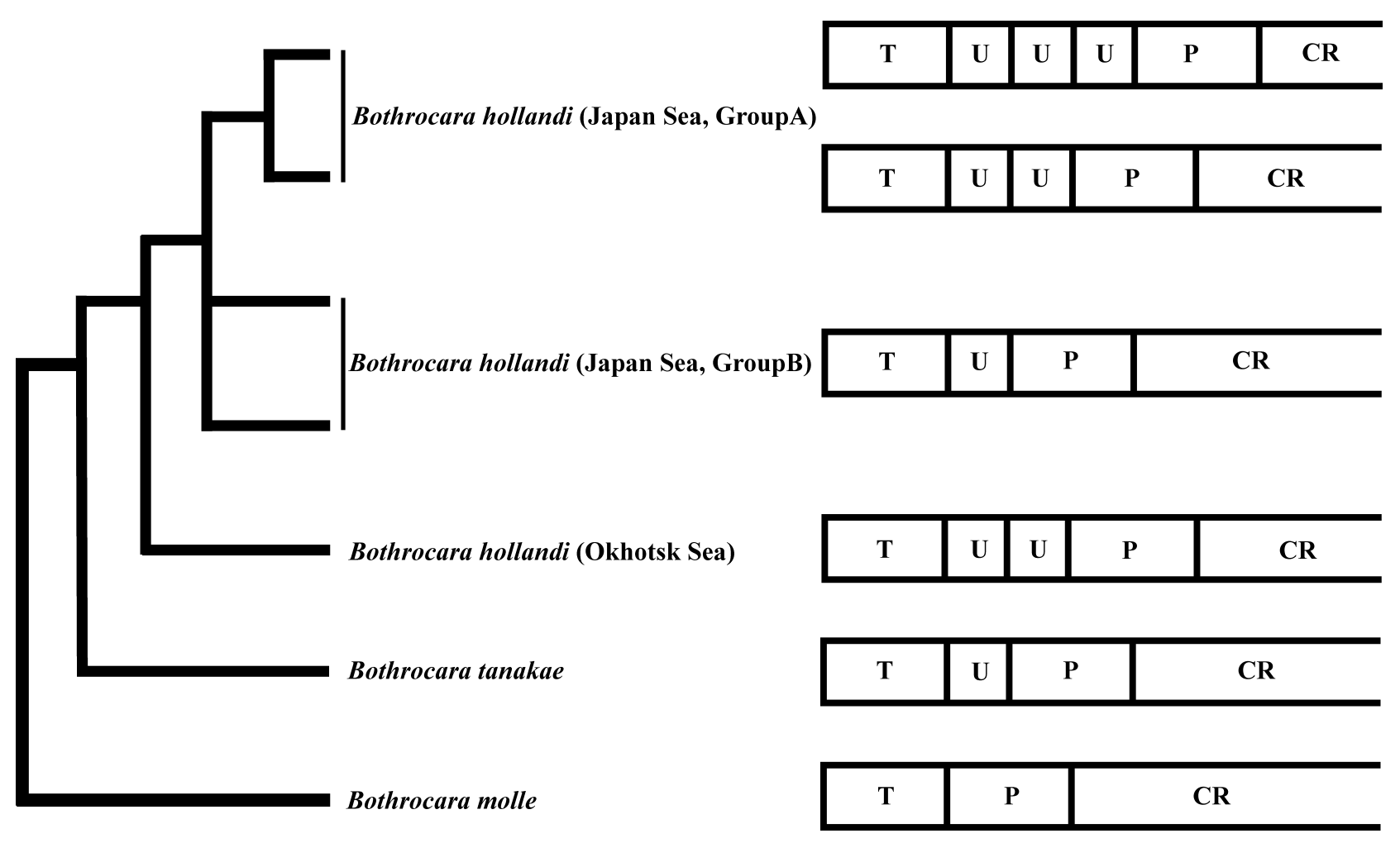

Fig. 1. Schematic illustration of the phylogenetic relationships among three groups of Bothrocara hollandi and two related species, which has been suggested by previous studies (Kojima et al. 2001: Kodama et al. 2008), and structures of the non-coding region where $\mathrm{T}, \mathrm{P}, \mathrm{U}$, and $\mathrm{CR}$ denote the $\mathrm{TRNA}^{\mathrm{Thr}}$ gene, $\mathrm{tRNA}^{\text {Pro }}$ gene, a unit of the non-coding region, and the control region, respectively. 
The non-coding region contained 1-3 tandem repeat units (Fig. 1). All B. tanakae specimens and Group B $B$. hollandi specimens had a single unit, and only two B. hollandi specimens from Group A had three units. The other specimens from Group A and all B. hollandi specimens from the Okhotsk Sea had two units. As summarized in Table 1, we obtained 18 types of units (units $0-17$, Fig. 2) and 20 permutations of those units from $B$. hollandi. From specimens of Group B, only three kinds of units were obtained and most of them (345 of 357) had an identical sequence (unit 1). This unit was obtained as either the first or second unit in Group A specimens. Only a single permutation of units (units 5+12) was shared between specimens of the Japan and Okhotsk seas. The nucleotide sequences of a unique unit of $B$. tanakae were not identical to those of any of the units of $B$. hollandi (Fig. 2).

Each unit exhibited high homology with the $5^{\prime}$-region of the tRNA ${ }^{\text {Pro }}$ gene (Fig. 2). In particular, the nucleotide sequence of unit 0 in Fig. 2 was considerably similar to that of this region. This result suggests that the units have originated from the duplication of the $5^{\prime}$-region of the tRNA ${ }^{\text {Pro }}$ gene. However, a reliable alignment could not be obtained since each unit is considerably short and variable.

Within the tRNA ${ }^{\text {Pro }}$ gene, nucleotide substitutions were detected at four positions, and five haplotypes were obtained (data not shown) among the 433 specimens of $B$. hollandi. Together with the non-coding region, a total of 25 haplotypes were obtained. The nucleotide sequences of
Table 1. Composition of haplotypes of the non-coding region between the genes for tRNA ${ }^{\text {Thr }}$ and tRNA ${ }^{\text {Pro }}$ of Bothrocara hollandi. Units are the same as those in Fig. 2 and the permutation is indicated in the order from the 5 '-end to 3 '-end.

\begin{tabular}{|c|c|c|c|}
\hline \multirow{2}{*}{ Permutation of units } & \multicolumn{2}{|c|}{ Japan Sea } & \multirow{2}{*}{ Okhotsk Sea } \\
\hline & Group A & Group B & \\
\hline 1 & & 345 & \\
\hline 2 & & 9 & \\
\hline 3 & & 3 & \\
\hline $1+10$ & 1 & & \\
\hline $1+17$ & 1 & & \\
\hline $4+10$ & 4 & & \\
\hline $5+1$ & 10 & & \\
\hline $5+8$ & 3 & & \\
\hline $5+9$ & 3 & & \\
\hline $5+10$ & 10 & & \\
\hline $5+11$ & 5 & & \\
\hline $5+12$ & 1 & & 14 \\
\hline $5+14$ & & & 2 \\
\hline $5+16$ & 1 & & \\
\hline $6+11$ & 5 & & \\
\hline $6+15$ & 1 & & \\
\hline $7+12$ & & & 3 \\
\hline $7+13$ & & & 6 \\
\hline $5+6+11$ & 1 & & \\
\hline $6+11+0$ & 1 & & \\
\hline
\end{tabular}

\begin{tabular}{|c|c|}
\hline Pro & TCAAAGAAAGGAGATTCTAACTCCCACCCCTAACTC \\
\hline 0 & TCAAAGAAAGAAGATTATAAA-CCCACCCCTAAC-C \\
\hline 1 & $-\mathrm{C}-\mathrm{AGAAAGAAGATTATAAA}-\mathrm{CCCACCCCTA-C-C}$ \\
\hline 2 & $-\mathrm{C}-$ AGAAAGAAGATTATAAA-CCCGCCCCTA-C-C \\
\hline 3 & $-\mathrm{C}-$ AGAAAGAAGATTATAAA-CCCCCCCCTA-C-C \\
\hline 4 & -C-AGAAAGAAGATTATAAA-CCCACCC-TA-CT- \\
\hline 5 & -C-AGAAAGAAGATTATAAA-CCCACCCCTA-CT- \\
\hline 6 & -C-AGAAAGAAGATTATAAA-CCCACCCCTAAC- \\
\hline 7 & -C-AGAAAGAAGATTATAAA-CCCACCCCTATT- \\
\hline 8 & -C-AGAAAGAAGATTATAAA-CCCACCCCTACCT- \\
\hline 9 & -C-AGAAAGAAGATTATAAA-CCCACCCCTA-CTC \\
\hline 10 & $-C-$ AGAAAGAAGATTATAAA-CCCACCCCTACC-C \\
\hline 11 & $-\mathrm{C}-\mathrm{AGAAAGAAGATTATAAA-CCCACCCCTAAC-C}$ \\
\hline 12 & -C-AGAAAGAAGATTATAAA-CCCACCCCTA-C- \\
\hline 13 & -C-AGAAAGAAGATTATAAA-CCCACCCCTA-T- \\
\hline 14 & -C-AAAAAGAAGATTATAAA-CCCACCCCTA-C- \\
\hline 15 & $-\mathrm{C}-\mathrm{AGAAAGAAGATTATAAA}-\mathrm{CCCACCCCAACC-C}$ \\
\hline 16 & -C-AGAAAGAAAATTATAAA-CCCACCCCTACCT- \\
\hline 17 & $-\mathrm{C}-\mathrm{TGAAAGAAGATTATAAA-CCCACCCCTACC-C}$ \\
\hline $\mathrm{Bt}$ & -CAAAGAAAGGAGATTCTAACTCCCACCCCTAATGC \\
\hline
\end{tabular}

Fig. 2. Nucleotide sequences of the $5^{\prime}$-end of the tRNA ${ }^{\text {Pro }}$ gene of Bothrocara hollandi and B. tanakae (Pro), units of the noncoding region of Bothrocara hollandi (0-17), and Bothrocara tanakae (Bt). Dashes denote alignment gaps. 
these 25 haplotypes and that of B. tanakae will appear in the GSDB, DDBJ, EMBL, and NCBI nucleotide sequence databases under the accession numbers AB374153-374178.

\section{Discussion}

Kojima et al. (2001) demonstrated that Bothrocara hollandi in the Japan Sea can be divided into two genetically distinct groups: Group A and Group B. The present study showed that all specimens of Group B had only one unit in the non-coding region between the tRNA ${ }^{\text {Thr }}$ and tRNA ${ }^{\text {Pro }}$ genes, while all the analyzed specimens of Group A had more than one unit. This result suggests that individuals of these two groups are genetically distinct from each other as stated by Kojima et al. (2001). As the median-joining network and molecular phylogenetic trees of the $B$. hollandi haplotypes suggested that Group A had diverged from Group B (Kojima et al. 2001, Kodama et al. 2008), the present result suggests that the duplication of the unit had occurred in the common ancestral population from which Group A individuals had evolved; this supports the theory of Group A monophyly stated by Kojima et al. (2001).

To date, Group A specimens have been sampled only from areas shallower than $1,100 \mathrm{~m}$. Kodama et al. (2008) estimated that the $B$. hollandi population of the Japan Sea were deviated from that of the Okhotsk Sea before the last glacial period. During the last glacial maximum (LGM; 27,000 to 17,000 years ago) when most of the Japan Sea was anoxic, ancestors of Group A would have inhabited the shallower areas of the Japan Sea which did not become anoxic (Gorbarenko \& Southon 2000, Itaki et al. 2004). Two whelks endemic to the Japan Sea, Buccinum tsubai Kuroda in Teramachi and Buccinum striatissimum Sowerby, which inhabit depths between 100 and $1,100 \mathrm{~m}$, are also suggested to have survived during the glacial periods in the shallower areas of the Japan Sea (Amano 2004, Iguchi et al. 2004, 2007). Ancestors of Group B might have survived during the last glacial maximum in other refuges in the Japan Sea.

Kojima et al. (2001) reported a lower genetic diversity in the CR for specimens of Group B as compared to those in Group A, and attributed it to a more severe reduction of genetic diversity under unsuitable environments of the habitats of the former group during the LGM. In the present study, a similar pattern was more notably observed for the non-coding region (Table 1) - the nucleotide sequences of the non-coding region of most Group B specimens (96.6\%) were identical (unit 1). This strongly suggests that a severe bottleneck might have occurred in the population size of an ancestral population of Group B during the LGM.

The close similarity of the units to the 5'-region of the tRNA $^{\text {Pro }}$ gene clearly reveals that the units of the non-coding region have originated from the duplication of the tRNA ${ }^{\text {Pro }}$ gene. To date, such repeats have been discovered only in B. hollandi and Bothrocara tanakae. Since B. tanakae, which is a sister species of $B$. hollandi, has a sin- gle unit in this region, similar to all the $B$. hollandi specimens of Group B, the common ancestor of $B$. hollandi probably would have had a single unit. The duplication of the unit is considered to have occurred two times within Group A. An additional single duplication of the unit is also considered to have occurred and to have been fixed in the monophyletic group of individuals in the Okhotsk Sea.

Because of the high evolutionary rate of the non-coding regions in the mitochondrial DNA, it can be used as an adequate genetic marker for phylogeographic studies focusing on relatively recent events such as Holocene events. Various non-coding regions have been reported from fish mitochondrial DNAs: tandem repeats (Lunt et al. 1998), duplication of CR (Lee et al. 2001), intergenic spacers (Shields \& Gust 1995, Bakke et al. 1999), and tRNA pseudogenes (Mabuchi et al. 2004). Exact alignment among nucleotide sequences of non-coding regions is rather difficult due to the limited length and high frequency of insertions, deletions, and duplications; nevertheless, it can enable us to reconstruct the population history in great detail. In the present study, we showed that the number of tandem repeat units can be used to confirm intraspecific phylogenetic relationships, which are often difficult to determine solely by nucleotide sequence analyses. By using non-coding regions of mitochondrial DNA, we intend to reveal the processes of formation of deep-sea benthic communities of the Japan Sea and neighboring sea regions.

\section{References}

Amano K (2004) Biogeography and the Pleistocene extinction of neogastropods in the Japan Sea. Palaeogeogr Palaeoclimatol Palaeoecol 202: 245-252.

Bakke I, Shields GF, Johansen S (1999) Sequence characterization of a unique intergenic spacer in Gadiformes mitochondrial DNA. Mar Biotech 1: 411-415.

Gorbarenko SA, Southon JR (2000) Detailed Japan Sea paleoceanography during the last $25 \mathrm{kyr}$ : constraints from AMS dating and $\delta^{18} \mathrm{O}$ of planktonic foraminifera. Palaeogeogr Palaeoclimatol Palaeoecol 156: 177-193.

Iguchi A, Ueno M, Maeda T, Minami T, Hayashi I (2004) Genetic population structure of the deep-sea whelk Buccinum tsubai in the Japan Sea. Fish Sci 70: 569-572.

Iguchi A, Takai S, Ueno M, Maeda T, Minami T, Hayashi I (2007) Comparative analysis on the genetic population structure of the deep-sea whelk Buccinum tsubai and Neptunea constricta in the Sea of Japan. Mar Biol 151: 31-39.

Itaki T, Ikehara K, Motoyama I, Hasegawa S (2004) Abrupt ventilation changes in the Japan Sea over the last $30 \mathrm{ky}$ : evidence from deep-dwelling radiolarians. Palaeogeogr Palaeoclimatol Palaeoecol 208: 263-278.

Kodama Y (2005) The genetic population structure of a deep-sea demersal fish, Bothrocara hollandi, in the Japan Sea and the Okhotsk Sea. Master thesis, University of Tokyo.

Kodama Y, Yanagimoto T, Shinohara G, Hayashi I, Kojima S (2008) Deviation age of a deep-sea demersal fish, Bothrocara hollandi, between the Japan Sea and the Okhotsk Sea. Mol Phy- 
logenet Evol 49: 682-687.

Kojima S, Segawa R, Hayashi I, Okiyama M (2001) Phylogeography of a deep-sea demersal fish, Bothrocara hollandi, in the Japan Sea. Mar Ecol Prog Ser 217: 135-143.

Lee JS, Miya M, Lee YS, Kim CG, Park EH, Aoki Y, Nishida M (2001) The complete DNA sequence of the mitochondrial genome of the self-fertilizing fish Rivulus marmoratus (Cyprinodontiformes, Rivulidae) and the first description of duplication of a control region in fish. Gene 280: 1-7.

Lunt DH, Whipple LE, Hyman BC (1998) Mitochondrial DNA variable number tandem repeats (VNTRs): utility and problems in molecular ecology. Mol Ecol 7: 1441-1455.

Mabuchi K, Miya M, Satoh TP, Westneat MW, Nishida M (2004) Gene rearrangements and evolution of tRNA pseudogenes in the mitochondrial genome of the parrotfish (Teleostei: Perciformes: Scaridae). J Mol Evol 59: 287-297.

Shields GF, Gust JR (1995) Lack of geographic structure in mitochondrial DNA sequences of Bering Sea walleye pollock, Theragra chalcogramma. Mol Mar Biol Biotech 4: 69-82. 